\title{
Evaluation of the Mann Assessment of Swallowing Ability in Elderly Patients with Pneumonia
}

\author{
Yasuo Chojin', Tatsuji Kato1, Mariko Rikihisa ${ }^{2}$, Masami Omori², Shingo Noguchi ${ }^{3,4}$, Kentaro \\ Akata $^{3}$, Takaaki Ogoshi ${ }^{3}$, Kazuhiro Yatera ${ }^{3,}$, Hiroshi Mukae ${ }^{3,5}$ \\ ${ }^{1}$ Department of Respiratory Medicine, Tobata Kyoritsu Hospital; ${ }^{2}$ Department of Rehabilitation, Tobata Kyoritsu \\ Hospital; ${ }^{3}$ Department of Respiratory Medicine, University of Occupational and Environmental Health, Japan; \\ ${ }^{4}$ Department of Respiratory Medicine, Wakamatsu Hospital of the University of Occupational and Environmental \\ Health, Japan; ${ }^{5}$ Department of Respiratory Medicine, Unit of Translational Medicine, Nagasaki University \\ Graduate School of Biomedical Sciences, Japan
}

[Received October 17, 2016; Revised December 26, 2016; Accepted January 2, 2017]

\begin{abstract}
Elderly pneumonia patients have various underlying diseases and social backgrounds, and it is difficult to predict their mortality using the current severity assessment tools. However, aspiration is a risk factor for mortality in pneumonia patients. In the evaluation of aspiration, endoscopic and video fluoroscopic methods are reliable but cannot be performed in all pneumonia patients. We evaluated the significance of the Mann Assessment of Swallowing Ability (MASA) in these patients. This study was prospectively performed between December 2014 and June 2015 , and all adult hospitalized patients with pneumonia were consecutively enrolled. The MASA score was evaluated soon after admission. The outcome measures were in-hospital mortality, a recurrence of pneumonia within 30 days, 6 month mortality, and the detection of antibiotic-resistant bacteria. A total of 153 patients were ultimately included. The proportion of in-hospital mortality was greater among the severe MASA score patients than normal score patients $(p<0.01)$, as was the proportion of recurrence of pneumonia $(p<0.01)$ and 6-month mortality $(p<0.01)$. In addition, patients with a moderate MASA score more often experienced recurrence of pneumonia than normal score patients $(p<0.05)$. Furthermore, patients with a mild MASA score more often experienced recurrence of pneumonia $(p<0.01)$ and 6-month mortality $(p<0.05)$ than normal score patients. The areas under the curve were $0.74(95 \%$ confidence interval $[\mathrm{CI}], \mathbf{0 . 6 7 - 0 . 8 2})$ for in-hospital mortality, $0.75(95 \% \mathrm{CI}, \mathbf{0 . 6 8 - 0 . 8 2})$ for recurrence of pneumonia, $0.72(95 \%$ Cl, 0.64-0.81) for 6-month mortality, and 0.60 (95\% CI, 0.46-0.73) for detection of antibiotic-resistant bacteria. A multivariate analysis showed an abnormal MASA score to be an independent risk factor for the recurrence of pneumonia $(p=0.001)$ and 6 -month mortality $(p=0.005)$. The MASA is useful for predicting the mortality and recurrence of pneumonia in elderly patients.
\end{abstract}

Key words: mann assessment of swallowing ability, elderly, aspiration risk, pneumonia, mortality, recurrence of pneumonia

Various severity assessment tools have been used to craft treatment strategies and predict mortality in the clinical practice of pneumonia, and the pneumonia severity index (PSI) and CURB-65 are commonly recommended in clinical practice [1,2]. However, elderly patients with pneumonia commonly have various factors that influence the treatment strategies and mortality, and the increasing number of elderly patients with pneumonia has hampered predicting mortality using these tools $[3,4]$. Furthermore, recent studies have underscored the importance of an

*Correspondence should be addressed to: Kazuhiro Yatera, M.D., Ph.D., Department of Respiratory Medicine, University of Occupational and Environmental Health, Japan. E-mail: yatera@med.uoeh-u.ac.jp

Copyright: ( 9 2017. This is an open-access article distributed under the terms of the Creative Commons Attribution License, which permits unrestricted use, distribution, and reproduction in any medium, provided the original author and source are credited. 
evaluation of comorbid diseases and social background for predicting the mortality $[5,6]$.

Comorbid diseases such as dementia and Parkinson's disease often cause dysphagia, which is a major risk factor for aspiration pneumonia [7-9]. Elderly patients with pneumonia are often complicated with several of these diseases; therefore, the clinical influence of aspiration should be considered in elderly patients with pneumonia, even when obvious episodes of aspiration have not been demonstrated.

Endoscopic and video fluoroscopic methods have proven to be reliable in the evaluation of dysphagia [10], but these techniques cannot be performed in all patients with pneumonia, often due to a poor general condition or inadequate hospital facilities. The bedside water swallow test is known to identify many of those with aspiration [11], but it cannot be performed in all cases due to the risk of oropharyngeal aspiration and provides little information to guide treatment.

The Mann Assessment of Swallowing Ability (MASA) was created by Mann in 2002 as an assessment tool for identifying eating and swallowing disorders [12] and is used in patients with acute stroke [13]. Currently, the utility of the MASA has been reported in patients with various underlying diseases [14,15], and its high sensitivity and specificity for detecting aspiration has also been reported [16]. In addition, the MASA can quantify the aspiration risk via a bedside procedure and accounts for the cognitive function, which is a risk factor for aspiration pneumonia [17].

In the present study, we prospectively investigated the significance of assessing the MASA in patients with pneumonia.

\section{MATERIALS AND METHODS}

\section{Study population}

This study was prospectively conducted at Tobata Kyoritsu Hospital (218 beds in Kitakyushu City, Japan) between December 2014 and June 2015, and all adult hospitalized patients with pneumonia were consecutively enrolled. The following patients were excluded: (1) those younger than 20 years old; (2) those with esophageal cancer; and (3) those not evaluated using the MASA. This study was approved by the ethics committee of Tobata Kyoritsu Hospital (No. 15-01) and was registered in a clinical trial registry (UMIN 000016179). All patients provided their written informed consent.

\section{Definitions of pneumonia}

Pneumonia was defined when the patient met all three of the following criteria: (1) at least one clinical symptom (fever, cough, sputum production, chest pain); (2) new infiltrates on chest radiography and/or computed tomography; and (3) a white blood cell count of $\geq 10,000 / \mu 1$ and/or increased levels of serum C-reactive protein. The definitions of community acquired pneumonia (CAP) and healthcare associated pneumonia (HCAP) were in accordance with the American Thoracic Society (ATS)/Infectious Disease Society of America (IDSA) guidelines [18].

\section{The Mann Assessment of Swallowing Ability}

The MASA consists of 24 items, and each measured score is converted into a weighted 5 or 10 points [12], which are then summed to a 200-point maximum score. The total scores are then used to define four categories of aspiration risk, as follows: 170-200, no abnormality; 149-169, mild; 141-148, moderate; $\leq 140$, severe. The MASA score was evaluated by expert speech-language-hearing therapists within three days after admission.

\section{Microbiological evaluation}

Bacterial cultures were performed using a semiquantitative method. The detection of bacteria was determined when the cultured bacterial volume from sputum samples was more than " $2+$ " [19]. In addition, the presence of bacteria was determined when blood or pleural effusion cultures and/or urinary antigen tests for Streptococcus pneumoniae or Legionella pneumophila serogroup I (Binax ${ }^{\circledR}$; Portland, ME, USA) were positive. In addition, methicillin-resistant Staphylococcus aureus (MRSA), Pseudomonas aeruginosa, extended spectrum $\beta$-lactamase (ESBL)-Escherichia coli, ESBL-Klebsiella pneumoniae, and Acinetobacter spp. were defined as antibiotic-resistant bacteria.

\section{Outcome measures}

The major outcomes were in-hospital mortality, a recurrence of pneumonia within 30 days (defined as the emergence of new pneumonia after remission of the preceding pneumonia [20]), and 6-month mortality. In addition, the detection of antibiotic-resistant bacteria was also evaluated. The rates of recurrence of pneumonia and 6-month mortality were assessed by consulting the medical records and/or interview. Patients were treated by their attending physician, and the choice of antibiotics was entirely decided by the attending physician. Initial treatment failure was defined as death during initial antibiotic therapy or a change in the antibiotics due to insufficient response to the initially prescribed antibiotics at the judgement of the attending physician. 


\section{Revised oral assessment guide}

The revised oral assessment guide (ROAG) consists of eight items (voice, lips, mucus membranes, tongue, gums, teeth, saliva, and swallow), and each item is scored from 1 (healthy) to 3 (severe problems), with a possible total sum ranging from 8 to 24 points [21]. The evaluation of the ROAG was performed by expert dentists and dental hygienist.

\section{Statistical analyses}

The STATA 14 software program (StataCorp LP, College Station, TX, USA) was used in this analysis, and Fisher's exact test for tables $(2 \times 2)$ and the Mann-Whitney U test were applied. $P<0.05$ was considered significant. The receiver operating characteristics (ROC) curves and areas under the curve (AUCs) were analyzed for each severity classification (normal, mild, moderate, and severe) according to the MASA score and each outcome. A univariate analysis was used to determine the ability of each variable to predict each outcome. A stepwise multiple logistic regression model was created for variables found to be significant $(p<0.05)$ in the univariate analysis to determine the variables with independent significant associations with each outcome.

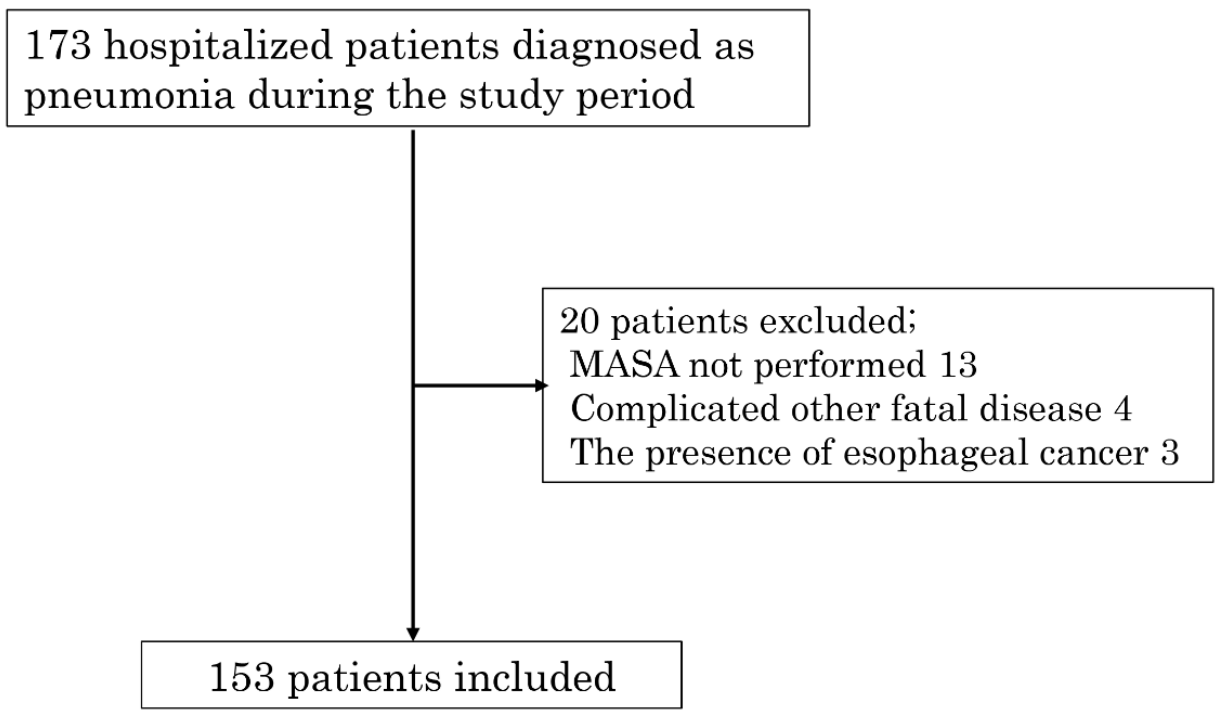

Figure 1. Flow chart.

\section{RESULTS}

\section{Patient characteristics}

A total of 173 hospitalized patients with pneumonia were enrolled, and 153 evaluated using the MASA were ultimately included in this analysis (Fig. 1). The clinical characteristics of these 153 patients are shown in Table 1 . The average age was $85.4 \pm 9.9$ years old, and the ratio of females was $62.7 \%$. In-hospital mortality was noted in 14 $(9.2 \%)$ patients, and all 14 patients died because of pneumonia. Six-month mortality was noted in 29 (22.8\%) patients, including $19(65.5 \%)$ patients who died due to pneumonia and 10 patients who died because of sepsis (2 patients), COPD (1), liver dysfunction (1), caducity (1), and unknown causes (5). Recurrence of pneumonia within
30 days was observed in $47(32.4 \%)$ patients. An abnormal MASA score was pointed out in 110 (71.9\%) patients. In addition, abnormal respiration was pointed out in all patients $(100 \%)$, followed by abnormal oral transit (86.9\%), abnormal tongue strength $(79.7 \%)$, and abnormal respiratory rate for swallowing $(79.1 \%)$ in each assessment item of the MASA (Table 2).

\section{Pathogen distribution}

The detected bacteria are listed in Table 3. Microbes were identified in 82 of $153(53.6 \%)$ patients, and $S$. pneumoniae (14.6\%) was the most commonly isolated, followed by S. aureus (13.4\%), Haemophilus influenzae $(13.4 \%)$, and E. coli $(13.4 \%)$. The ratio of antibioticresistant bacteria was $19.5 \%$. 
Table 1. Characteristics of 153 patients with pneumonia.

\begin{tabular}{|c|c|c|}
\hline \multirow{2}{*}{$\begin{array}{l}\text { Age (years), mean } \pm \text { SD } \\
\text { Female sex; } n(\%)\end{array}$} & \multicolumn{2}{|c|}{$85.4 \pm 9.9$} \\
\hline & 96 & $(62.7)$ \\
\hline Performance status $\geq 3$; n (\%) & 138 & $(90.2)$ \\
\hline HCAP; n $(\%)$ & 100 & $(65.4)$ \\
\hline \multicolumn{3}{|l|}{ Comorbidity; n (\%) } \\
\hline Malignancy & 38 & $(24.8)$ \\
\hline Cerebrovascular disease & 87 & $(56.9)$ \\
\hline Laryngopharynx disorder & 26 & $(17.0)$ \\
\hline Chronic cardiovascular disease & 69 & $(45.1)$ \\
\hline Chronic respiratory disease & 58 & $(37.9)$ \\
\hline Chronic liver disease & 6 & $(3.9)$ \\
\hline Chronic kidney disease & 8 & $(5.2)$ \\
\hline Diabetes mellitus & 23 & $(15.0)$ \\
\hline Dementia & 131 & $(85.6)$ \\
\hline \multicolumn{3}{|l|}{ Clinical parameters; n (\%) } \\
\hline Orientation disturbance (confusion) & 9 & $(5.9)$ \\
\hline Respiratory failure & 90 & $(58.8)$ \\
\hline Systolic BP $<90 \mathrm{mmHg}$ or diastolic $\mathrm{BP} \leq 60 \mathrm{mmHg}$ & 3 & $(2.0)$ \\
\hline Body temperature $\leq 35$ or $\geq 40{ }^{\circ} \mathrm{C}$ & 8 & $(5.2)$ \\
\hline Pulse rate $\geq 125$ beats $/ \mathrm{min}$ & 17 & $(11.1)$ \\
\hline \multicolumn{3}{|l|}{ Laboratory findings } \\
\hline $\mathrm{BUN} \geq 10.7 \mathrm{mmol} / \mathrm{L}$ & 76 & $(49.7)$ \\
\hline Glucose $\geq 13.9 \mathrm{mmol} / \mathrm{L}$ & 7 & (4.6) \\
\hline Hematocrit $<30 \%$ & 23 & $(15.0)$ \\
\hline Albumin $<3.0 \mathrm{~g} / \mathrm{dl}$ & 52 & $(34.0)$ \\
\hline \multicolumn{3}{|l|}{ PSI score; n (\%) } \\
\hline I-III & 20 & $(13.1)$ \\
\hline VI & 65 & $(42.5)$ \\
\hline $\mathrm{V}$ & 68 & $(44.4)$ \\
\hline Gastrogavage & 5 & $(3.3)$ \\
\hline ICU admission & 13 & $(8.5)$ \\
\hline Length of hospital stay (days) & 19.1 & \pm 11.9 \\
\hline In-hospital mortality; n (\%) & 14 & $(9.2)$ \\
\hline Recurrence of pneumonia within 30 days; $\mathrm{n}(\%)^{\dagger 1}$ & 47 & $(32.4)$ \\
\hline 6-month mortality ${ }^{\dagger 2}$ & 29 & $(22.8)$ \\
\hline
\end{tabular}


Table 2. Number of abnormality of the clinical assessment items of the Mann Assessment of Swallowing Ability.

\begin{tabular}{lrl}
\hline Clinical assessment items & Number of abnormality \\
\hline Alertness & 69 & $(45.1)$ \\
Cooperation & 95 & $(62.1)$ \\
Auditory comprehension & 119 & $(77.8)$ \\
Respiration & 153 & $(100)$ \\
Respiratory rate for swallowing & 121 & $(79.1)$ \\
Dysphasia & 83 & $(54.2)$ \\
Dyspraxia & 41 & $(26.8)$ \\
Dysarthria & 103 & $(67.3)$ \\
Saliva & 34 & $(22.2)$ \\
Lip Seal & 95 & $(62.1)$ \\
Tongue movement & 105 & $(68.6)$ \\
Tongue strength & 122 & $(79.7)$ \\
Tongue coordination & 131 & $(85.6)$ \\
Oral preparation & 86 & $(56.2)$ \\
Gag & 116 & $(75.8)$ \\
Palate & 87 & $(56.9)$ \\
Bolus clearance & 85 & $(55.6)$ \\
Oral transit & 133 & $(86.9)$ \\
Cough reflex & 109 & $(71.2)$ \\
Voluntary cough & 101 & $(66.0)$ \\
Voice & 95 & $(62.1)$ \\
Trachea & 1 & $(0.7)$ \\
Pharyngeal phase & 103 & $(67.3)$ \\
Pharyngeal response & 27 & $(17.6)$ \\
\hline
\end{tabular}

\section{In-hospital mortality according to the MASA}

All 153 patients were included in this analysis. Among the patients with normal, mild, moderate, and severe MASA scores, in-hospital mortality occurred in 0 of $43(0.0 \%), 1$ of $31(3.2 \%), 1$ of $8(12.5 \%)$, and 12 of $71(16.9 \%)$ patients, respectively (Fig. 2A). Patients with a severe score showed a significantly higher mortality rate than those with a normal score $(p<0.01)$. In addition, there were significant differences in the mortality rate between mild score and severe score patients $(p<0.05)$.

\section{Recurrence of pneumonia within 30 days according to the MASA}

Six patients who did not admit remission of the first pneumonia and 2 lacking an outcome evaluation were not included in this analysis, leaving 145 patients for the evaluation. Among the patients with normal, mild, moderate, and severe MASA scores, the recurrence of pneumonia within 30 days occurred in 1 of $42(2.4 \%), 9$ of $29(31.0 \%), 3$ of 8 (37.5\%), and 34 of $66(51.5 \%)$ patients, respectively (Fig. 2B). The recurrence of pneumonia within 30 days differed significantly between those with normal scores and those with mild $(p<0.01)$, moderate $(p<0.05)$, and severe scores $(p<0.05)$.

Table 3. Microbes identified in patients with pneumonia.

\begin{tabular}{|c|c|c|}
\hline Staphylococcus aureus & 11 & (13.4) \\
\hline MSSA & 5 & $(6.1)$ \\
\hline MRSA & 6 & (7.3) \\
\hline Staphylococcus epidermidis & 1 & $(1.2)$ \\
\hline Streptococcus pneumoniae & 12 & (14.6) \\
\hline Enterococcus spp. & 1 & $(1.2)$ \\
\hline Moraxella catarrhalis & 3 & $(3.7)$ \\
\hline Haemophilus influenzae & 11 & $(13.4)$ \\
\hline BLNAR & 6 & $(7.3)$ \\
\hline Escherichia coli & 11 & $(13.4)$ \\
\hline ESBL & 2 & $(2.4)$ \\
\hline Klebsiella pneumoniae & 7 & $(8.5)$ \\
\hline ESBL & 2 & (2.4) \\
\hline Pseudomonas aeruginosa & 5 & $(6.1)$ \\
\hline Enterobacter spp. & 2 & (2.4) \\
\hline Acinetobacter spp. & 1 & $(1.2)$ \\
\hline Legionella pneumophila & 1 & $(1.2)$ \\
\hline Anaerobic bacteria & 4 & $(4.9)$ \\
\hline Oral bacteria & 65 & (79.3) \\
\hline Others & 3 & $(3.7)$ \\
\hline Detected antibiotic-resistant bacteria $^{\dagger}$ & 16 & $(19.5)$ \\
\hline \multicolumn{3}{|c|}{$\begin{array}{l}\text { Data are presented as n (\%) unless otherwise stated. The } \\
\text { percentages refer to } 82 \text { patients in whom some bacteria were } \\
\text { identified. } \\
\text { MSSA: methicillin-sensitive Staphylococcus aureus, MRSA: } \\
\text { methicillin-resistant Staphylococcus aureus, BLNAR: } \beta \text { - } \\
\text { lactamase non-producing ampicillin-resistant, ESBL: } \\
\text { Extended spectrum } \beta \text {-lactamase } \\
\dagger \text { MRSA, ESBL-producing bacteria, Pseudomonas } \\
\text { aeruginosa, and Acinetobacter spp. were defined as } \\
\text { antibiotic-resistant bacteria }\end{array}$} \\
\hline
\end{tabular}

\section{Six-month mortality according to the MASA}

Fourteen patients who died during hospitalization and 12 lacking an outcome evaluation were not included in this analysis, leaving 127 patients for the evaluation. Among the patients with normal, mild, moderate, and severe MASA scores, 6-month mortalities occurred in 1 of 38 (2.6\%), 6 of $28(21.4 \%), 1$ of $5(20.0 \%)$, and 21 of 56 (37.5\%) patients, respectively (Fig. 2C). Patients with a severe score showed a significantly higher mortality rate than those with a normal score $(p<0.01)$. In addition, there were also significant differences in the mortality rate between the mild score and normal score patients $(p<$ $0.05)$. 
A

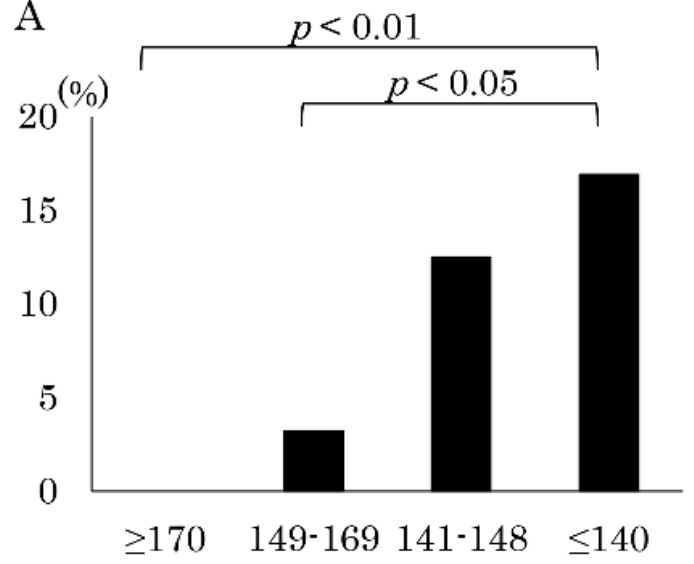

C

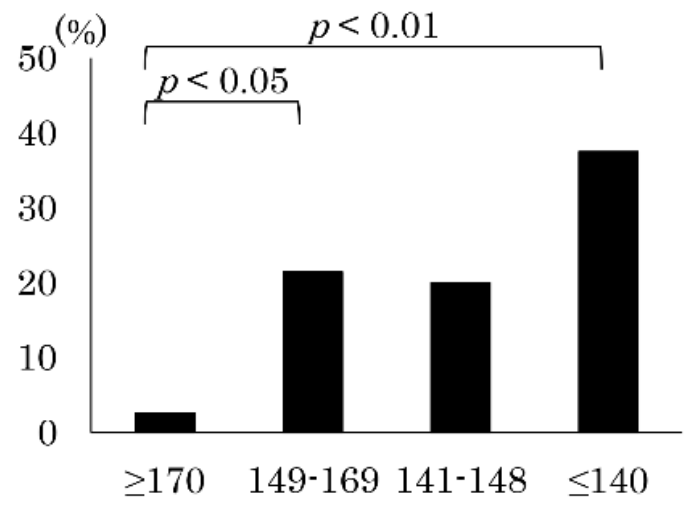

B

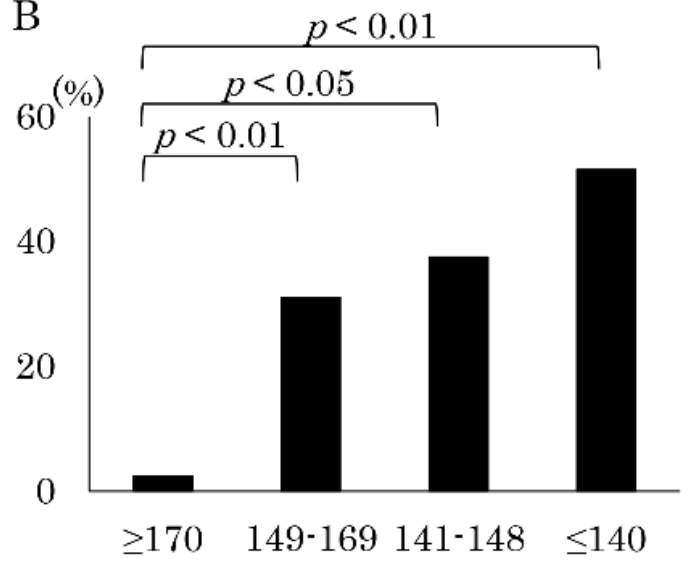

D

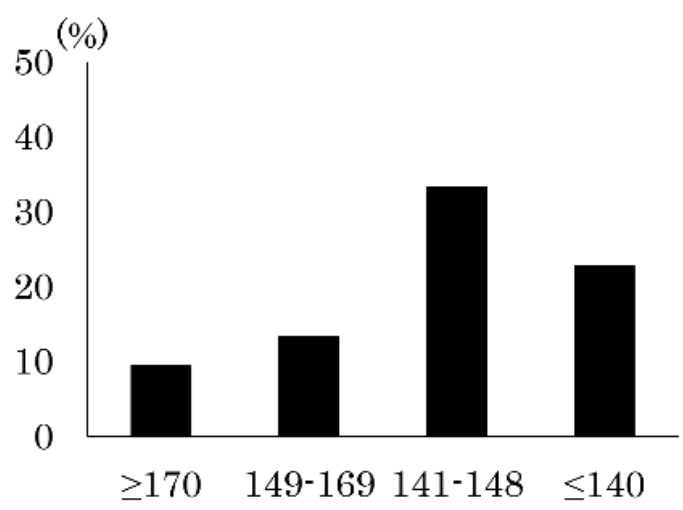

Figure 2. Prediction of each parameter according to the MASA score. A) In-hospital mortality, B) Recurrence of pneumonia within 30 days, C) 6-month mortality, D) Detection of antibiotic-resistant bacteria.

Detection of antibiotic-resistant bacteria according to the MASA

Eighty-two patients were included in this analysis. Among the patients with normal, mild, moderate, and severe MASA scores, antibiotic-resistant bacteria were detected in 2 of 20 (10.0\%), 2 of 15 (13.3\%), 1 of 3 (33.3\%), and 10 of $44(22.7 \%)$ patients, respectively (Fig. 2D). There were no marked differences in the detection rates based on MASA score.

\section{Prognostic accuracy for each outcome according to the MASA}

The ROC curve between the MASA score severity classification and each outcome is shown in Figure 3. The AUCs using the ROC curve were 0.74 (95\% confidence interval [CI], 0.67-0.82), 0.75 (95\% CI, 0.68-0.82), 0.72 $(95 \% \mathrm{Cl}, 0.64-0.81)$, and 0.60 (95\% CI, $0.46-0.73)$ for the in-hospital mortality, recurrence of pneumonia within 30 days, 6-month mortality, and the detection of antibioticresistant bacteria, respectively.

\section{Multivariate analysis of risk factors for in-hospital mortality}

According to a univariate analysis, the significant risk factors for in-hospital mortality were cerebrovascular disease $(p=0.037)$, orientation disturbance $(p=0.02)$, hematocrit $\leq 30 \%(p=0.031)$, and serum albumin $\leq 3.0$ $\mathrm{g} / \mathrm{dl}(p=0.018)$, with no significance detected for MASA score (Supplmental Table 1). According to a multivariate analysis of these 4 items, the significant risk factors for in-hospital mortality were cerebrovascular disease $(p=$ $0.024)$ and orientation disturbance $(p=0.020)$ (Table 4A). 

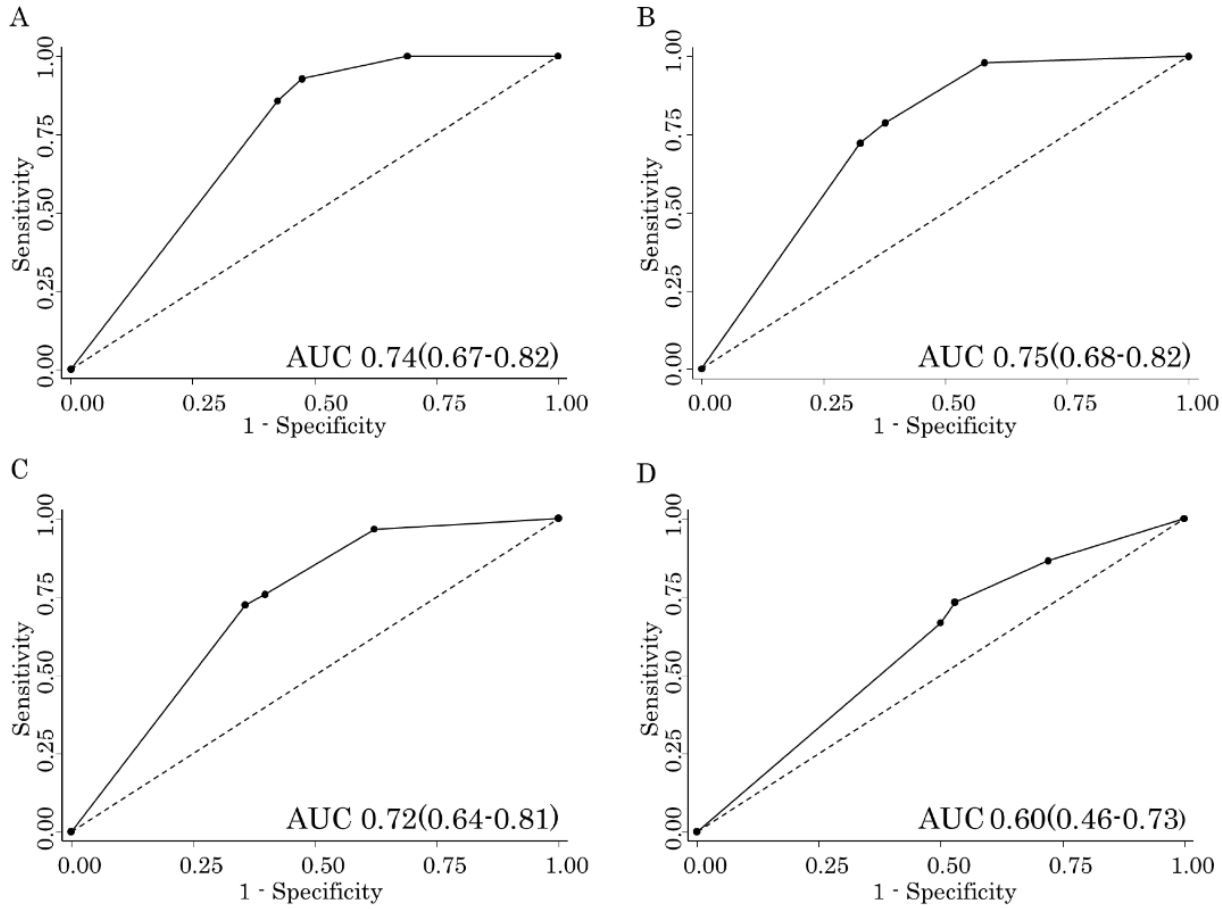

Figure 3. The receiver operating characteristics curve for each parameter according to the MASA score. A) In-hospital mortality, B) Recurrence of pneumonia within 30 days, C) 6-month mortality, D) Detection of antibiotic-resistant bacteria.

\section{Multivariate analysis of risk factors for the recurrence of pneumonia within 30 days}

A univariate analysis showed the MASA score $(\leq 169)(p$ $=0.001)$ to be a significant risk factor for the recurrence of pneumonia within 30 days, in addition to cerebrovascular disease $(p=0.032)$, dementia $(p=0.028)$, inappropriate initial antibiotics $(p=0.034)$, and serum albumin $\leq 3.0 \mathrm{~g} / \mathrm{dl}(p=0.023)$ (Suppmetnal Table 2). A multivariate analysis of these 5 items showed only the MASA score $(p=0.001)$ to be an independent risk factor for the recurrence of pneumonia within 30 days (Table 4B).

\section{Multivariate analysis of risk factors for six-month mortality}

A univariate analysis showed the MASA score $(\leq 169)(p$ $=0.006)$ to be a significant risk factor for 6-month mortality, in addition to female sex $(p=0.031)$, chronic liver disease $(p=0.023)$, inappropriate initial antibiotics $(p=0.005)$, and serum albumin $\leq 3.0 \mathrm{~g} / \mathrm{dl}(p \leq 0.001)$ (Suppmental Table 3). A multivariate analysis of these 5 items showed the MASA score $(p=0.005)$ to be an independent risk factor for 6-month mortality, in addition to female sex $(p=0.025)$, inappropriate initial antibiotics $(p=0.037)$, and albumin $\leq 3.0 \mathrm{~g} / \mathrm{dl}(p=0.001)$ (Table 4C).

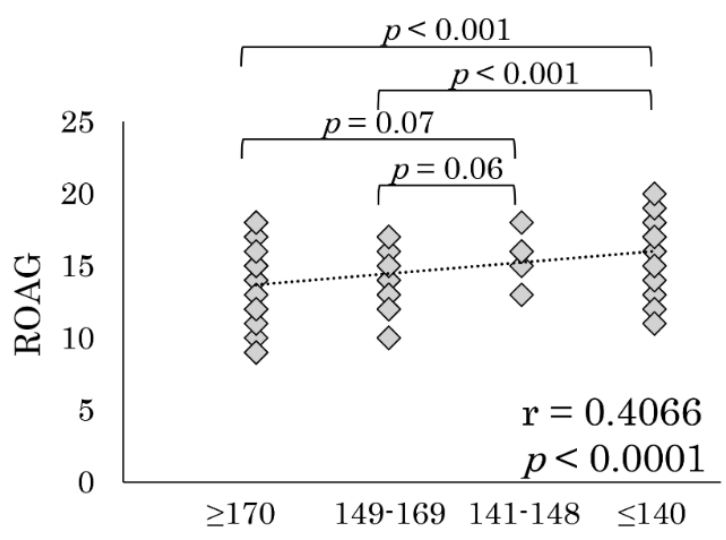

Figure 4. The revised oral assessment guide according to MASA 
Table 4. Multivariate analysis of risk factors for each outcome.

A. In-hospital mortality

\begin{tabular}{lccc}
\hline & Odds ratio & $\mathbf{9 5 \%}$ Confidence interval & $\boldsymbol{p}$ value \\
\hline Cerebrovascular disease & 7.48 & $1.31-42.84$ & 0.024 \\
Orientation disturbance & 11.04 & $1.46-83.66$ & 0.020 \\
Hematocrit $<30 \%$ & 3.64 & $0.93-14.18$ & 0.063 \\
Albumin $<3.0 \mathrm{~g} / \mathrm{dl}$ & 2.67 & $0.77-9.24$ & 0.121 \\
\hline
\end{tabular}

B. Recurrence of pneumonia within 30 days

\begin{tabular}{lccc}
\hline & Odds ratio & 95\% Confidence interval & $\boldsymbol{p}$ value \\
\hline MASA score $\leq 169$ & 36.20 & $4.17-314.67$ & 0.001 \\
Cerebrovascular disease & 1.93 & $0.84-4.40$ & 0.119 \\
Dementia & 0.79 & $0.12-5.12$ & 0.808 \\
Inappropriate initial antibiotics & 2.40 & $0.98-5.86$ & 0.055 \\
Albumin $<3.0 \mathrm{~g} / \mathrm{dl}$ & 2.09 & $0.90-4.84$ & 0.085 \\
\hline & & & \\
C. Six-month mortality & Odds ratio & $\mathbf{9 5 \%}$ Confidence interval & $\boldsymbol{p}$ value \\
\hline & 0.30 & $0.10-0.86$ & 0.025 \\
Female & 21.29 & $2.49-182.22$ & 0.005 \\
MASA score $\leq 169$ & 10.49 & $0.94-117.07$ & 0.056 \\
Chronic liver disease & 3.25 & $1.07-9.86$ & 0.037 \\
Inappropriate initial antibiotics & 5.83 & $2.02-16.87$ & 0.001 \\
Albumin $<3.0 \mathrm{~g} / \mathrm{dl}$ & &
\end{tabular}

\section{Correlation between the MASA and ROAG}

The ROAG score was significantly higher in patients with a severe MASA score than in those with normal and mild scores (Fig. 4). In addition, there was a significant but weak correlation $(r=0.41, p<0.0001)$ between the MASA score and ROAG.

\section{DISCUSSION}

The present study prospectively analyzed the usefulness of an aspiration risk evaluation according to the MASA score for predicting the mortality and recurrence of pneumonia in patients with pneumonia. We first demonstrated that the MASA can be useful for predicting the mortality and the recurrence of pneumonia in clinical practice.

In this study, we showed that the MASA score was not an independent risk factor for in-hospital mortality but was an independent risk factor for 6-month mortality in a multivariate analysis (Table 4). Recently, Komiya et al. reported that aspiration pneumonia was related to the short- and long-term mortality; however, in their systematic review of aspiration risks, the results in each study varied widely with respect to the short-term mortality, which was strongly influenced by the differences in the study size, population and the definition of aspiration pneumonia [22]. While the MASA is known to be a useful tool for predicting aspiration in elderly people, there have been no reports of the usefulness of the MASA in patients with pneumonia $[15,16]$. The results of this study suggest that the MASA can identify aspiration risks in patients with pneumonia and help predict the mortality of patients with pneumonia, although further investigations are needed with respect to the shortterm mortality. Whereas, pneumonia was not the only cause of long-term mortality in this study. Repetitive aspiration pneumonia is usually related to a reduction in physical activity and malnutrition, and the long-term mortality in patients with aspiration pneumonia is influenced by various host factors [23]. Therefore, while not all deaths in this study were due to pneumonia, we 
nevertheless believe that the MASA is a useful tool for predicting the mortality in clinical practice, although whether the MASA can predict the long-term mortality due to pneumonia remains controversial.

We clarified in our study that an abnormal MASA score was an independent risk factor for predicting not only the mortality but also the recurrence of pneumonia. Generally, it is known that recurrence of pneumonia is not uncommon in elderly patients, and the presence of aspiration is an independent risk factor of recurrence of pneumonia and readmission due to pneumonia [24-26]. We think that patients with low MASA scores show a high aspiration risk, and similar to its utility in predicting mortality, the MASA can predict the recurrence of pneumonia.

In this study, we used all 24 items of the MASA scoring system, but the relative complexity of this system may be its weak point. Recent reports of the MASA have shown the usefulness of the modified MASA in various groups [14, 16, 27], and Ohira et al. reported that 17 of its 24 items are associated with aspiration risk [17]. However, according to our results, the abnormal items were necessarily inconsistent with their results; for example, "respiratory rate for swallowing" and "gag" were abnormal for almost 70-80\% cases, although these items were not deemed significant for aspiration in the study of Ohira et al. [16]. Therefore, we need to investigate how the items are associated with predicting the mortality and recurrence in the patients with pneumonia.

Aspiration is a risk factor for detecting antibioticresistant bacteria [26, 28]. In this regard, the MASA score did not have strong power for detecting antidrug-resistant bacteria in this study. Whether antibiotic-resistant bacteria cultured in sputum are truly the pathogens of pneumonia remains controversial, and we also previously found that the MRSA relatively infrequently helped to determine the pathogenesis of pneumonia using the molecular method [29, 30]. In addition, the mortality associated with pneumonia is reported to be primarily due to advanced age and comorbidities and not an increased prevalence of resistant pathogens [23, 31]. Thus, the MASA might be a good assessment tool for predicting the mortality and recurrence of pneumonia without any influence on detecting antibiotic-resistant bacteria in cultivation.

Aside from the MASA, a female gender, oriental disturbance, cerebrovascular disease, chronic liver disease, dementia, a low level of serum albumin or hematocrit, and inappropriate initial antibiotics were also risk factors for mortality and the recurrence of pneumonia, according to a multivariate analysis. Regarding gender, it was reported that men are at a greater risk of aspiration pneumonia than women in systematic review, although various opinions have been reported with respect to gender [32]. The significant differences between genders might influence the aspiration risk, although whether the 6-month mortality was associated with aspiration was necessarily unclear. In contrast, age was not a significant risk factor for these three outcomes on a multivariate analysis in this study. Although age is generally thought to be a major risk factor for predicting mortality and/or recurrence of pneumonia [25, 33], the results of the present study might have been influenced by the higher rate of advanced-age patients than in other studies. Results similar to our observations were reported by Manabe et al., who found that age was not a significant risk factor for aspiration pneumonia among elderly patients [17].

Dysphagia is a common chronic problem with respect to older age, dementia, and chronic diseases, and the swallowing function has been reported to decline as the age increases, naturally leading to aspiration [34]. In addition, the recovery of dysphagia by swallowing rehabilitation alone might be difficult. However, the importance of oral care has been reported to help prevent the recurrence of pneumonia, thereby helping prevent repetitive pneumonia and reduce the mortality [35, 36]. The MASA score had a weak correlation with the ROAG, which is one of the evaluation of the oral function status [37, 38], in this study (Fig. 4). Therefore, we think that the MASA might be useful for suggesting an adequate time to start oral care in patients with pneumonia, thereby helping to reduce the rate of recurrence of pneumonia. In addition, it may be important for patients with low MASA scores to receive adequate evaluation and support in various aspects of their lives, such as meal contents, posture during meals, meal time, and care level [39]. Furthermore, pharyngeal electrical stimulation and clarithromycin administration might also be useful for treating patients with dysphagia [39, 40]. In this respect, further investigations are needed to clarify the usefulness of the MASA.

Several limitations associated with the present study warrant mention. First, although this study was a prospective study, it was a single-center trial. Second, we used the cut-off levels determined in acute stroke patients, but more optimal cut-off levels should be identified for predicting mortality in pneumonia patients in the future, such as the proposed optimal cut-off point (122 points) for predicting aspiration in dependent older adults [16]. Third, the MASA score might be influenced by the skills of each scorer and the timing of the examination, although the evaluation of MASA score was performed by only a few expert therapists at as early a stage of hospitalization as possible in the present study. Fourth, we cannot exclude the short-term influence of pneumonia itself for the MASA score because acute respiratory insufficiencies may lead to short-lived dysphagia. However, we believe 
that our results in this study are still significant for evaluating the usefulness of the MASA score at hospital admission in predicting the mortality and the recurrence of pneumonia in clinical practice.

In conclusion, the MASA is a useful tool for predicting the recurrence of pneumonia and the mortality in clinical practice of elderly people with pneumonia. However, further multicenter studies should be performed to confirm our results in patients with pneumonia, and easier assessment tools for assessing aspiration risks that can be widely used might still be needed, since the MASA is relatively complex.

Suppmental Table 1. A univariate analysis of the in-hospital mortality.

\begin{tabular}{|c|c|c|c|}
\hline & Odds ratio & 95\% Confidence interval & $p$ value \\
\hline Age $\geq 75$ years & 1.46 & $0.18-11.98$ & 0.727 \\
\hline Age $\geq 85$ years & 2.47 & $0.66-9.27$ & 0.179 \\
\hline Female sex & 0.77 & $0.25-2.35$ & 0.650 \\
\hline HCAP & 0.68 & $0.22-2.08$ & 0.500 \\
\hline MASA score $\leq 169$ & 1.00 & & \\
\hline Performance status $\geq 3$ & 1.00 & & \\
\hline MMSE $\leq 26$ & 0.98 & $0.29-3.29$ & 0.967 \\
\hline Neoplastic disease & 0.81 & $0.21-3.07$ & 0.757 \\
\hline Cerebrovascular disease & 5.12 & $1.10-23.73$ & 0.037 \\
\hline Gastroesophageal disorder & 0.80 & $0.17-3.80$ & 0.778 \\
\hline Chronic heart disease & 1.24 & $0.41-3.73$ & 0.699 \\
\hline Chronic respiratory disease & 0.63 & $0.19-2.11$ & 0.453 \\
\hline Chronic liver disease & 1.00 & & \\
\hline Chronic kidney disease & 1.45 & $0.17-12.72$ & 0.737 \\
\hline Collagen disease & 10.61 & $0.63-179.80$ & 0.102 \\
\hline Diabetes mellitus & 0.94 & $0.20-4.49$ & 0.935 \\
\hline Dementia & 2.31 & $0.29-18.63$ & 0.431 \\
\hline Sleeping medications & 2.41 & $0.75-7.81$ & 0.141 \\
\hline ACE inhibitor drugs & 2.41 & $0.47-12.44$ & 0.294 \\
\hline Inhaled corticosteroid & 1.00 & & \\
\hline Gastrogavage & 2.60 & $0.27-25.0$ & 0.409 \\
\hline Orientation disturbance & 6.05 & $1.33-27.54$ & 0.020 \\
\hline $\mathrm{BUN} \geq 21 \mathrm{mg} / \mathrm{dl}$ & 1.93 & $0.62-6.06$ & 0.258 \\
\hline Respiratory rate $\geq 30$ breaths $/ \mathrm{min}$ & 2.02 & $0.58-6.99$ & 0.268 \\
\hline $\begin{array}{l}\text { Systolic BP }<90 \mathrm{mmHg} \text { or diastolic } \mathrm{BP} \leq \\
60 \mathrm{mmHg}\end{array}$ & 1.00 & & \\
\hline Body temperature $\geq 40$ or $\leq 35^{\circ} \mathrm{C}$ & 1.45 & $0.17-12.7$ & 0.737 \\
\hline Pulse rate $\geq 125$ beats $/ \mathrm{min}$ & 1.38 & $0.28-6.76$ & 0.693 \\
\hline $\mathrm{SpO}_{2} \leq 90 \%, \mathrm{PaO}_{2} \leq 60 \mathrm{mmHg}$ & 1.84 & $0.55-6.17$ & 0.321 \\
\hline Pleural effusion & 1.92 & $0.63-5.90$ & 0.253 \\
\hline $\begin{array}{l}\text { Detected history of antibiotic-resistant } \\
\text { bacteria }\end{array}$ & 1.96 & $0.50-7.73$ & 0.338 \\
\hline Inappropriate initial antibiotics & 2.15 & $0.70-6.61$ & 0.183 \\
\hline Antibiotic-resistant bacteria & 2.14 & $0.48-9.49$ & 0.315 \\
\hline Hematocrit $<30 \%$ & 3.73 & $1.12-12.40$ & 0.031 \\
\hline Albumin $<3.0 \mathrm{~g} / \mathrm{dl}$ & 4.02 & $1.27-12.70$ & 0.018 \\
\hline $\mathrm{Na}<130 \mathrm{mEq} / \mathrm{ml}$ & 1.45 & $0.17-12.72$ & 0.737 \\
\hline Glucose $\geq 250 \mathrm{mg} / \mathrm{dl}$ & 4.47 & $0.78-25.52$ & 0.092 \\
\hline
\end{tabular}

HCAP: healthcare-associated pneumonia, MASA: The Mann Assessment of Swallowing Ability, MMSE: Mini Mental State Examination, ACE: angiotensin-converting enzyme, BUN: blood urea nitrogen, BP: blood pressure 
Suppmental Table 2. A univariate analysis of recurrence of pneumonia within 30 days of admission.

\begin{tabular}{|c|c|c|c|}
\hline & Odds ratio & $95 \%$ Confidence interval & $p$ value \\
\hline Age $\geq 75$ years & 1.85 & $0.49-7.00$ & 0.362 \\
\hline Age $\geq 85$ years & 1.34 & $0.65-2.76$ & 0.434 \\
\hline Female sex & 0.58 & $0.28-1.17$ & 0.129 \\
\hline HCAP & 0.82 & $0.40-1.68$ & 0.585 \\
\hline MASA score $\leq 169$ & 33.09 & $4.38-249.78$ & 0.001 \\
\hline Performance status $\geq 3$ & 1.00 & & \\
\hline $\mathrm{MMSE} \leq 26$ & 0.99 & $0.46-2.16$ & 0.989 \\
\hline Neoplastic disease & 1.25 & $0.56-2.75$ & 0.585 \\
\hline Cerebrovascular disease & 2.22 & $1.07-4.61$ & 0.032 \\
\hline Gastroesophageal disorder & 0.65 & $0.24-1.76$ & 0.398 \\
\hline Chronic heart disease & 0.52 & $0.25-1.06$ & 0.072 \\
\hline Chronic respiratory disease & 0.93 & $0.45-1.92$ & 0.853 \\
\hline Chronic liver disease & 4.47 & $0.79-25.31$ & 0.091 \\
\hline Chronic kidney disease & 2.95 & $0.63-13.73$ & 0.169 \\
\hline Collagen disease & 2.11 & $0.13-34.47$ & 0.601 \\
\hline Diabetes mellitus & 1.23 & $0.48-3.18$ & 0.668 \\
\hline Dementia & 5.41 & $1.20-24.31$ & 0.028 \\
\hline Sleeping medications & 1.46 & $0.62-3.42$ & 0.389 \\
\hline ACE inhibitor drugs & 0.89 & $0.22-3.59$ & 0.866 \\
\hline Inhaled corticosteroid & 1.00 & & \\
\hline Gastrogavage & 3.27 & $0.53-20.29$ & 0.203 \\
\hline Orientation disturbance & 1.27 & $0.29-5.55$ & 0.752 \\
\hline $\mathrm{BUN} \geq 21 \mathrm{mg} / \mathrm{dl}$ & 0.84 & $0.42-1.70$ & 0.635 \\
\hline Respiratory rate $\geq 30$ breaths $/ \mathrm{min}$ & 0.78 & $0.30-2.02$ & 0.705 \\
\hline Systolic BP $<90 \mathrm{mmHg}$ or diastolic $\mathrm{BP} \leq 60 \mathrm{mmHg}$ & 1.04 & $0.092-11.81$ & 0.973 \\
\hline Body temperature $\geq 40$ or $\leq 35^{\circ} \mathrm{C}$ & 0.33 & $0.039-2.85$ & 0.316 \\
\hline Pulse rate $\geq 125$ beats $/ \mathrm{min}$ & 0.85 & $0.28-2.58$ & 0.779 \\
\hline $\mathrm{SpO}_{2} \leq 90 \%, \mathrm{PaO}_{2} \leq 60 \mathrm{mmHg}$ & 1.44 & $0.70-2.94$ & 0.320 \\
\hline Pleural effusion & 1.17 & $0.54-2.53$ & 0.681 \\
\hline Detected history of antibiotic-resistant bacteria & 1.38 & $0.50-3.83$ & 0.532 \\
\hline Inappropriate initial antibiotics & 2.28 & $1.06-4.87$ & 0.034 \\
\hline Antibiotic-resistant bacteria & 0.99 & $0.77-1.25$ & 0.904 \\
\hline Hematocrit $<30 \%$ & 1.93 & $0.77-4.88$ & 0.161 \\
\hline Albumin $<3.0 \mathrm{~g} / \mathrm{dl}$ & 2.31 & $1.12-4.77$ & 0.023 \\
\hline $\mathrm{Na}<130 \mathrm{mEq} / \mathrm{ml}$ & 2.19 & $0.52-9.15$ & 0.284 \\
\hline Glucose $\geq 250 \mathrm{mg} / \mathrm{dl}$ & 1.00 & & \\
\hline
\end{tabular}

HCAP: healthcare-associated pneumonia, MASA: The Mann Assessment of Swallowing Ability, MMSE: Mini Mental State Examination, ACE: angiotensin-converting enzyme, BUN: blood urea nitrogen, BP: blood pressure 
Suppmental Table 3. A univariate analysis of six-month mortality.

\begin{tabular}{|c|c|c|c|}
\hline & Odds ratio & 95\% Confidence interval & $p$ value \\
\hline Age $\geq 75$ years & 0.88 & $0.22-3.48$ & 0.851 \\
\hline Age $\geq 85$ years & 2.05 & $0.83-5.08$ & 0.120 \\
\hline Female sex & 0.39 & $0.17-0.92$ & 0.031 \\
\hline HCAP & 1.13 & $0.46-2.75$ & 0.791 \\
\hline MASA score $\leq 169$ & 16.98 & $2.22-130.10$ & 0.006 \\
\hline Performance status $\geq 3$ & 1.00 & & \\
\hline MMSE $\leq 26$ & 0.85 & $0.34-2.08$ & 0.715 \\
\hline Neoplastic disease & 0.93 & $0.35-2.44$ & 0.881 \\
\hline Cerebrovascular disease & 2.05 & $0.85-4.94$ & 0.111 \\
\hline Gastroesophageal disorder & 0.35 & $0.08-1.63$ & 0.182 \\
\hline Chronic heart disease & 0.56 & $0.24-1.32$ & 0.185 \\
\hline Chronic respiratory disease & 1.22 & $0.52-2.83$ & 0.651 \\
\hline Chronic liver disease & 7.68 & $1.33-44.35$ & 0.023 \\
\hline Chronic kidney disease & 2.71 & $0.57-12.89$ & 0.210 \\
\hline Collagen disease & 1.00 & & \\
\hline Diabetes mellitus & 0.76 & $0.23-2.48$ & 0.652 \\
\hline Dementia & 5.06 & $0.64-40.06$ & 0.125 \\
\hline Sleeping medications & 1.41 & $0.52-3.81$ & 0.494 \\
\hline ACE inhibitor drugs & 0.40 & $0.05-3.35$ & 0.400 \\
\hline Inhaled corticosteroid & 0.59 & $0.12-2.81$ & 0.504 \\
\hline Gastrogavage & 1 & & \\
\hline Orientation disturbance & 1.00 & & \\
\hline $\mathrm{BUN} \geq 21 \mathrm{mg} / \mathrm{dl}$ & 0.55 & $0.23-1.30$ & 0.172 \\
\hline Respiratory rate $\geq 30$ breaths $/ \mathrm{min}$ & 0.82 & $0.25-2.68$ & 0.742 \\
\hline Systolic BP $<90 \mathrm{mmHg}$ or diastolic $\mathrm{BP} \leq 60 \mathrm{mmHg}$ & 1.00 & & \\
\hline Body temperature $\geq 40$ or $\leq 35^{\circ} \mathrm{C}$ & 1.00 & & \\
\hline Pulse rate $\geq 125$ beats $/ \mathrm{min}$ & 1.00 & & \\
\hline $\mathrm{SpO}_{2} \leq 90 \%, \mathrm{PaO}_{2} \leq 60 \mathrm{mmHg}$ & 0.85 & $0.37-1.96$ & 0.701 \\
\hline Pleural effusion & 1.69 & $0.71-4.06$ & 0.238 \\
\hline Detected history of antibiotic-resistant bacteria & 1.65 & $0.52-5.20$ & 0.395 \\
\hline Inappropriate initial antibiotics & 3.61 & $1.48-8.82$ & 0.005 \\
\hline Antibiotic-resistant bacteria & 3.41 & $0.88-13.25$ & 0.077 \\
\hline Hematocrit $<30 \%$ & 2.80 & $0.96-8.19$ & 0.060 \\
\hline Albumin $<3.0 \mathrm{~g} / \mathrm{dl}$ & 4.89 & $2.03-11.78$ & $\leq 0.001$ \\
\hline $\mathrm{Na}<130 \mathrm{mEq} / \mathrm{ml}$ & 2.71 & $0.57-12.89$ & 0.210 \\
\hline Glucose $\geq 250 \mathrm{mg} / \mathrm{dl}$ & 0.84 & $0.09-7.82$ & 0.878 \\
\hline
\end{tabular}

HCAP: healthcare-associated pneumonia, MASA: The Mann Assessment of Swallowing Ability, MMSE: Mini Mental State Examination, ACE: angiotensin-converting enzyme, BUN: blood urea nitrogen, BP: blood pressure 


\section{Acknowledgments}

We thank Hideki Nakagawa (Speech-Language-Hearing Therapist, Tobata Kyoritsu Hospital, Fukuoka, Japan), Misato Kojiro (Speech-Language-Hearing Therapist, Tobata Kyoritsu Hospital, Fukuoka, Japan), Miki Kawanishi (Speech-Language-Hearing Therapist, Tobata Kyoritsu Hospital, Fukuoka, Japan), Norihiko Furuta (Dentist, Tobata Kyoritsu Hospital, Fukuoka, Japan), Michiyo Nakatani (Dental Hygienist, Tobata Kyoritsu Hospital, Fukuoka, Japan), and Kuniko Sakamoto (Dental Hygienist, Tobata Kyoritsu Hospital, Fukuoka, Japan).

\section{References}

[1] Fine MJ, Auble TE, Yealy DM, Hanusa BH, Weissfeld LA, Singer DE, et al (1997). A prediction rule to identify low-risk patients with community-acquired pneumonia. N Engl J Med, 336(4): 243-250.

[2] Lim WS, van der Eerden MM, Laing R, Boersma WG, Karalus N, Town GI, et al (2003). Defining community acquired pneumonia severity on presentation to hospital: an international derivation and validation study. Thorax, 58(5): 377-382.

[3] Jeong BH, Koh WJ, Yoo H, Um SW, Suh GY, Chung MP, et al (2013). Performances of prognostic scoring systems in patients with healthcare-associated pneumonia. Clin Infect Dis, 56(5): 625-632.

[4] Falcone M, Corrao S, Venditti M, Serra P, Licata G (2011). Performance of PSI, CURB-65, and SCAP scores in predicting the outcome of patients with community-acquired and healthcare-associated pneumonia. Intern Emerg Med, 6(5): 431-436.

[5] Shindo Y, Ito R, Kobayashi D, Ando M, Ichikawa M, Goto Y, et al (2015). Risk factors for 30-day mortality in patients with pneumonia who receive appropriate initial antibiotics: an observational cohort study. Lancet Infect Dis, 15(9): 1055-1065.

[6] Maruyama T, Fujisawa T, Okuno M, Toyoshima H, Tsutsui K, Maeda H, et al (2013). A new strategy for healthcare-associated pneumonia: a 2-year prospective multicenter cohort study using risk factors for multidrugresistant pathogens to select initial empiric therapy. Clin Infect Dis, 57(10): 1373-1383.

[7] DiBardino DM, Wunderink RG (2015). Aspiration pneumonia: a review of modern trends. J Crit Care, 30(1): 40-48.

[8] Marik PE, Kaplan D (2003). Aspiration pneumonia and dysphagia in the elderly. Chest, 124(1): 328-336.

[9] Cabre M, Serra-Prat M, Force L, Almirall J, Palomera E, Clave P (2014). Oropharyngeal dysphagia is a risk factor for readmission for pneumonia in the very elderly persons: observational prospective study. J Gerontol A Biol Sci Med Sci, 69(3): 330-337.

[10] Langmore SE, Schatz K, Olson N (1991). Endoscopic and videofluoroscopic evaluations of swallowing and aspiration. Ann Otol Rhinol Laryngol, 100(8): 678-681.
[11] Brodsky MB, Suiter DM, Gonzalez-Fernandez M, Michtalik HJ, Frymark TB, Venediktov R, et al (2016). Screening Accuracy for Aspiration Using Bedside Water Swallow Tests: A Systematic Review and MetaAnalysis. Chest, 150(1): 148-163.

[12] Mann G (2002). MASA, the mann assessment of swallowing ability: Cengage Learning.

[13] Antonios N, Carnaby-Mann G, Crary M, Miller L, Hubbard H, Hood K, et al (2010). Analysis of a physician tool for evaluating dysphagia on an inpatient stroke unit: the modified Mann Assessment of Swallowing Ability. J Stroke Cerebrovasc Dis, 19(1): 49-57.

[14] Carnaby GD, Crary MA (2014). Development and validation of a cancer-specific swallowing assessment tool: MASA-C. Support Care Cancer, 22(3): 595-602.

[15] Gonzalez-Fernandez M, Sein MT, Palmer JB (2011). Clinical experience using the Mann assessment of swallowing ability for identification of patients at risk for aspiration in a mixed-disease population. Am J Speech Lang Pathol, 20(4): 331-336.

[16] Ohira M, Ishida R, Maki Y, Ohkubo M, Sugiyama T, Sakayori T, et al (2016) Evaluation of a dysphagia screening system based on the Mann Assessment of Swallowing Ability for use in dependent older adults. Geriatr Gerontol Int.

[17] Manabe T, Teramoto S, Tamiya N, Okochi J, Hizawa N (2015). Risk Factors for Aspiration Pneumonia in Older Adults. PLoS One, 10(10): e0140060.

[18] American Thoracic Society, Infectious Diseases Society of America (2005). Guidelines for the management of adults with hospital-acquired, ventilator-associated, and healthcare-associated pneumonia. Am J Respir Crit Care Med, 171(4): 388-416.

[19] Noguchi S, Yatera K, Kawanami T, Yamasaki K, Naito $\mathrm{K}$, Akata K, et al (2015). The clinical features of respiratory infections caused by the Streptococcus anginosus group. BMC Pulm Med, 15: 133.

[20] Ishida T, Tachibana H, Ito A, Yoshioka H, Arita M, Hashimoto T (2012). Clinical characteristics of nursing and healthcare-associated pneumonia: a Japanese variant of healthcare-associated pneumonia. Intern Med, 51(18): 2537-2544.

[21] Andersson P, Hallberg IR, Renvert S (2002). Inter-rater reliability of an oral assessment guide for elderly patients residing in a rehabilitation ward. Spec Care Dentist, 22(5): 181-186.

[22] Komiya K, Rubin BK, Kadota JI, Mukae H, Akaba T, Moro H, et al (2016). Prognostic implications of aspiration pneumonia in patients with community acquired pneumonia: A systematic review with metaanalysis. Sci Rep, 6: 38097.

[23] Komiya K, Ishii H, Kadota J (2014). Healthcareassociated Pneumonia and Aspiration Pneumonia. Aging Dis 6(1): 27-37.

[24] Cabre M, Serra-Prat M, Force L, Almirall J, Palomera E, Clave $\mathrm{P}$ (2014). Oropharyngeal dysphagia is a risk factor for readmission for pneumonia in the very elderly persons: observational prospective study. J Gerontol A Biol Sci Med Sci, 69(3): 330-337. 
[25] Hayashi M, Iwasaki T, Yamazaki Y, Takayasu H, Tateno $\mathrm{H}$, Tazawa S, et al (2014). Clinical features and outcomes of aspiration pneumonia compared with non-aspiration pneumonia: a retrospective cohort study. J Infect Chemother, 20(7): 436-442.

[26] Metersky ML, Frei CR, Mortensen EM (2016). Predictors of Pseudomonas and methicillin-resistant Staphylococcus aureus in hospitalized patients with healthcare-associated pneumonia. Respirology, 21(1): 157-163.

[27] Nakamori M, Hosomi N, Ishikawa K, Imamura E, Shishido T, Ohshita T, et al (2016). Prediction of Pneumonia in Acute Stroke Patients Using Tongue Pressure Measurements. PLoS One, 11(11): e0165837.

[28] Chalmers JD, Taylor JK, Singanayagam A, Fleming GB, Akram AR, Mandal P, et al (2011). Epidemiology, antibiotic therapy, and clinical outcomes in health careassociated pneumonia: a UK cohort study. Clin Infect Dis, 53(2): 107-113.

[29] Noguchi S, Mukae H, Kawanami T, Yamasaki K, Fukuda K, Akata K, et al (2015). Bacteriological assessment of healthcare-associated pneumonia using a clone library analysis. PLoS One, 10(4): e0124697.

[30] Kawanami T, Yatera K, Yamasaki K, Noguchi S, Fukuda K, Akata K, et al (2016). Clinical impact of methicillin-resistant staphylococcus aureus on bacterial pneumonia: cultivation and $16 \mathrm{~S}$ ribosomal RNA gene analysis of bronchoalveolar lavage fluid. BMC Infect Dis, 16: 155-016-1493-3.

[31] Chalmers JD, Rother C, Salih W, Ewig S (2014). Healthcare-associated pneumonia does not accurately identify potentially resistant pathogens: a systematic review and meta-analysis. Clin infect Dis, 58(3): 330339.
[32] van der Maarel-Wierink CD, Vanobbergen JN, Bronkhorst EM, Schols JM, de Baat C (2011). Risk factors for aspiration pneumonia in frail older people: a systematic literature review. J Am Med Dir Assoc, 12(5): 344-354.

[33] Shindo Y, Ito R, Kobayashi D, Ando M, Ichikawa M, Goto Y, et al (2015). Risk factors for 30-day mortality in patients with pneumonia who receive appropriate initial antibiotics: an observational cohort study. Lancet Infect Dis, 15(9): 1055-1065.

[34] Ebihara S, Sekiya H, Miyagi M, Ebihara T, Okazaki T (2016). Dysphagia, dystussia, and aspiration pneumonia in elderly people. J Thorac Dis, 8(3): 632-639.

[35] Dang TT, Majumdar SR, Marrie TJ, Eurich DT (2015). Recurrent pneumonia: a review with focus on clinical epidemiology and modifiable risk factors in elderly patients. Drugs Aging, 32(1): 13-19.

[36] Yoneyama T, Yoshida M, Ohrui T, Mukaiyama H, Okamoto H, Hoshiba K, et al (2002). Oral care reduces pneumonia in older patients in nursing homes. J Am Geriatr Soc, 50(3): 430-433.

[37] Shiraishi A, Yoshimura Y, Wakabayashi H, Tsuji Y (2016). Poor oral status is associated with rehabilitation outcome in older people. Geriatr Gerontol Int

[38] Ribeiro MT, Ferreira RC, Vargas AM, Ferreira e Ferreira E (2014). Validity and reproducibility of the revised oral assessment guide applied by community health workers. Gerodontology, 31(2): 101-110.

[39] Inoue M (2015). Dysphagia Rehabilitation in Japan. J Nutr Sci Vitaminol (Tokyo), 61 Suppl: S72-3.

[40] Yoshikawa H, Komiya K, Umeki K, Kadota J (2014). Long-term macrolide antibiotic therapy may prevent the development of pneumonia in the elderly. J Palliat Med, 17(7): 749-750 